\section{Retinopathy of prematurity: are we screening too many babies?}

MRK Mathew, Al Fern and R Hill

were the only significant risk factors. During this 8-year period there was no significant decrease in the number of babies screened for ROP and the overall incidence of all stages of the disease has remained constant. In the present series a lower incidence of severe ROP was noted compared to most previous studies. Our experience from this study suggests the need for further refinement of screening guidelines in order to focus screening on the vision-threatening stages of ROP.

Eye (2002) 16, 538-542. doi:10.1038/

sj.eye. 6700031

Keywords: screening; retinopathy of prematurity; birthweight; gestational age

\section{Introduction}

With advancement in neonatal care units, early detection of retinopathy of prematurity (ROP) in premature and very-low-birth-weight infants is important. Numerous studies have reported an increased risk of ROP in prematurely born infants, ${ }^{1,2,3}$ but only a few have been long-term and strictly populationbased. ${ }^{4,5}$ The 1995 Royal College of Ophthalmologists (RCO) guidelines for screening for ROP includes babies under $1500 \mathrm{~g}$ and gestational age $<32$ weeks and provides an effective and efficient means of detecting treatable ROP. These criteria present a considerable workload to the ophthalmologist and various authors have suggested it may be possible to lower the criteria and reduce the screened population of babies. ${ }^{6-11}$ The aim of the present study was to find out whether birthweight $<1251$ grams and gestational age $<30$ weeks could provide a safe and efficient means of detecting treatable ROP. The study retrospectively tried to ascertain the incidence and associated risk factors that may contribute to the management 
of babies with ROP in the Lanarkshire District, Scotland, UK.

\section{Materials and methods}

A retrospective, hospital-records-based study of all neonates born before 32 weeks gestation or birthweight $<1500$ grams between 1 January 1992 and 31 December 99 in a geographically defined population of approximately one half of a million was undertaken in a central Scottish region in the United Kingdom. Lanarkshire District has a population of approximately 546800 and there were 54880 live births over the period of 1992-1999. The neonatal intensive care unit, Bellshill Maternity Hospital, Bellshill, Lanarkshire caters to the needs of the Lanarkshire Acute hospitals trust and adjoining areas. Annually approximately 5200 neonates are managed by this unit.

During the period between 1 January 1992 and 31 December 1999, there were 2189 preterm births. These premature infants were treated with nasal-continuous positive airway pressure (N-CPAP) as primary respiratory supporting system and were continuously monitored for oxygen tension $\left(\mathrm{pO}_{2} 8.0-12.0 \mathrm{kPa}\right)$.

All babies born before 32 weeks gestation or birthweight $<1500$ grams, were referred for ROP screening. Newborn babies who satisfied the Royal College of Ophthalmologists (RCO) guidelines for screening for retinopathy of prematurity criteria ${ }^{12}$ were examined before hospital discharge and after oxygen administration was terminated at the neonatal intensive care unit, Bellshill Maternity Hospital, Bellshill, Lanarkshire.

The initial examination was performed 5-7 weeks postnatally. An eyelid speculum and scleral indentation was used in all examinations. All children were screened for ROP by the same ophthalmologist (AIF) during this period and classified according to the most advanced stage of ROP using the International classification for ROP (The Committee for the Classification of Prematurity 1984). ${ }^{13}$ The ophthalmologist attended the neonatal unit on a weekly basis to assess the at-risk premature babies. If ROP was detected, the examinations were repeated at weekly intervals until the peripheral retina was vascularized normally.

The sex of the babies, history of multiple births, duration of oxygen treatment, mean age at detection, gestational age and birthweight were noted. In any patient with threshold retinopathy of prematurity (ROP) laser indirect photocoagulation or cryotherapy was performed. ${ }^{14}$ Patients with sight-threatening ROP or those who required treatment returned for frequent follow-up visits until regression was noted.

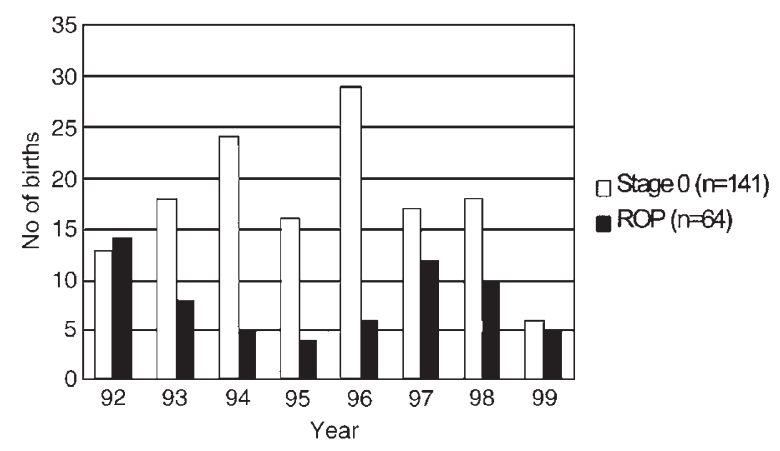

Figure 1 The frequency of babies with or without ROP ( $n=$ 205).

\section{Results}

A total of 205 infants born before 32 weeks gestation or birthweight $<1500$ grams, were referred for ROP screening in the neonatal intensive care unit, Bellshill Maternity Hospital, Bellshill, Lanarkshire (Figure 1). There were 98 male and 107 female babies. In this study population there were 117 ROP cases per 100000 live births.

The mean age at first examination was $5.5 \pm 2$ weeks of life. The mean birth weight and gestational age was $1205 \pm 32$ grams and $28 \pm 3$ weeks respectively. The year-wise distribution of babies screened, mean birth weight and gestational age are shown in Figure 2. During ROP screening a total of 64/205 (31.2\%) babies were noted to have ROP: 27 (13.2\%) babies had stage 1; $24(11.7 \%)$ babies suffered from stage $2 ; 10$ (4.8\%) developed stage 3 ROP when examined before hospital discharge and after oxygen administration was terminated. The median days of oxygen treatment was 6 days (range $0-48$ days). The

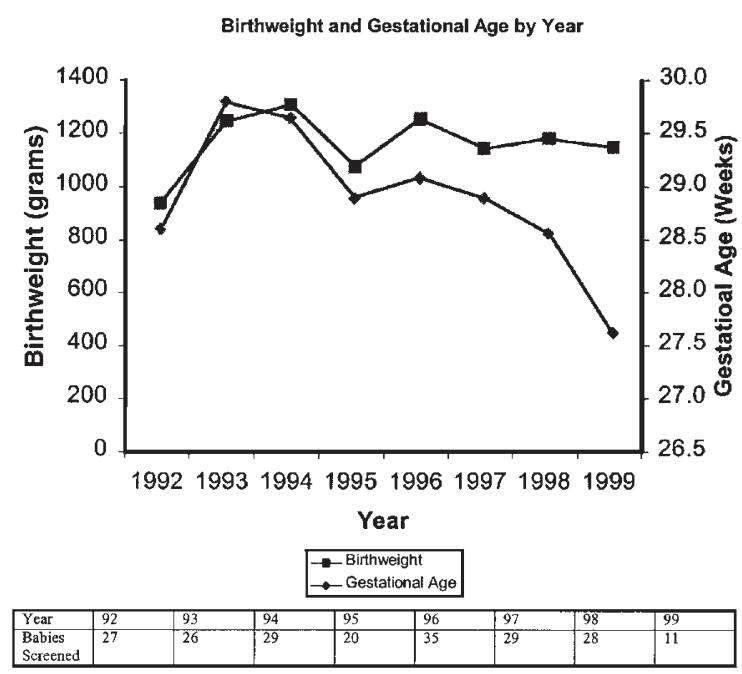

Figure 2 The year-wise distribution of babies screened, average birthweight $(\mathrm{g})$ and gestational age (weeks). 
possible relationship to different transcutaneous oxygen levels and assisted ventilation was not analysed in this series.

Table 1 shows the birthweight and gestational age of babies with $(n=64)$ and without $(n=141)$ ROP. Babies with stage 1 or stage 2 ROP had no more than Zone II ROP. There were $4.8 \%(10 / 205)$ babies with stage 3 disease and all had a birth weight $<1000 \mathrm{~g}$ and gestational age $<28$ weeks while those who developed threshold ROP (3/205) had a birth weight below $900 \mathrm{~g}$ and gestational age below 26 weeks.

The infants with threshold ROP underwent treatment: two babies underwent laser indirect photocoagulation, which was facilitated by scleral depression; cryopexy under general anaesthesia was done in one case with a non-dilating pupil and media haze. Total regression of disease was achieved in all three cases and was noted within 6 weeks of treatment. Subsequently one baby died and another developed an intraventricular haemorrhage.

The number of babies screened with the inclusion criterion of birthweight $<1251 \mathrm{~g}$ or a gestational age $<30$ wks was also examined. A birth weight of $<1251$ g was noted in $56.6 \%$ (116) babies of whom $51 \%$ (59) were with ROP. Similarly there were $60 \%$ (123) babies with a gestational age $<30$ weeks of whom $46 \%$ (56) had ROP. A total of $73 \%(150 / 205)$ babies examined had a birthweight $<1251 \mathrm{~g}$ or a gestational age $<30$ wks.

Of the babies with no ROP, 59.5\% (84) had a birthweight $>1250 \mathrm{~g}$ and $52.5 \%$ (74) were over 30 weeks gestational age. This compared to those babies with ROP where only $8 \%$ (5) were $>1250 \mathrm{~g}$ and $12.5 \%$ (8) had a gestational age above 30 weeks. Using the screening criteria of birthweight $<1251 \mathrm{~g}$ and a gestational age of $<30$ weeks would have resulted in the screening programme having a sensitivity of $84 \%$ and a specificity of $75 \%$.

It was also noted that while only $16.5 \%(34 / 205)$ of the babies examined had a birth weight $<1000 \mathrm{~g}$ or a gestational age $<28$ wks, $82 \%(28 / 34)$ of these babies had one of the stages of ROP and all the stage 3 and threshold cases were included in this group.

Linear regression analysis was performed to assess the relationship between ROP and risk factors involved including sex of the babies, multiple births, duration of oxygen treatment, birthweight and gestational age. The only factors found to be significantly associated with increasing severity of ROP were birth weight $(P<$ $0.001)$ and gestational age $(P<0.005)$.

\section{Discussion}

In the present hospital-records-based study, a total of 205 neonates born before 32 weeks gestation or birthweight $<1500 \mathrm{~g}$, between 1 January 1992 and 31 December 1999, were screened for ROP in the neonatal intensive care unit, Bellshill Maternity Hospital, Bellshill, Lanarkshire. This is the main maternity hospital for the district providing a service to a population of 550000 .

The aim of the study was to determine the underlying rate of ROP in this population and to determine if changing the screening criteria would increase the sensitivity of the screening programme. Slevin et al showed that during ROP screening, infants displayed increased neurobehavioral activity $(P<0.01)$ and crying $(P<0.01)$. The increased activity and crying coincided with the invasive part of the procedure. They concluded that ROP screening is distressing for preterm infants. ${ }^{15}$ Various authors ${ }^{16-18}$ have highlighted the underlying costs of screening premature babies and the screening is an additional commitment for an already overstretched ophthalmic department. Anything that would reduce the frequency of undertaking this task would be welcome.

The incidence of all stages of ROP is shown in Figure 1. There was no significant decrease or increase in the number of babies referred annually for screening. Similarly there was no significant change in the incidence of ROP throughout the 8 years. Only 11 babies required screening in 1999 but this would appear to be a variation on normal and not indicative of an underlying trend. The subsequent year (not reported) has shown numbers similar to those of the previous 7 years.

The study would appear to have identified a lower incidence of stage 3 ROP $(4.8 \%)$ than most other

Table 1 Birthweight and gestational age of babies with $(n=64)$ and without $(n=141)$ ROP

\begin{tabular}{lccccccccc}
\hline No ROP & $<28$ wks & $28-29$ wks & $30-31$ wks & Total & ROP & $<28$ wks & $28-29$ wks & 30-31 wks & Total \\
\hline$<1000 \mathrm{~g}$ & 6 & 7 & 4 & 15 & $<1000 \mathrm{~g}$ & 28 & 6 & 2 & 36 \\
$1000-1250 \mathrm{~g}$ & 6 & 16 & 18 & 42 & $1000-1250 \mathrm{~g}$ & 8 & 12 & 3 & 23 \\
$1251-1500 \mathrm{~g}$ & 3 & 29 & 52 & 84 & $1251-1500 \mathrm{~g}$ & & 2 & 3 & 5 \\
Total & 15 & 52 & 74 & 141 & Total & 36 & 20 & 8 & 64 \\
$(n=141)$ & & & & & & & & &
\end{tabular}


published figures. The incidence of stage 3 disease in other studies varies between 2-20\%, ${ }^{9-11}$ although the lower figure quoted by Haugen et $a l^{9}$ was a population-based study similar to our own. $\mathrm{Ng}$ YK et $a l^{19}$ in a study from Birmingham, UK showed an incidence of $2.2 \%$. There was no obvious reason to account for a lower incidence than expected. This may be a feature of the relatively small number of babies screened throughout the eight years but the figures probably give an accurate picture of the situation in a district general hospital serving its own local population. No baby presented subsequently with advanced disease and it must be assumed that these results are a true measure of the prevalence of ROP in the Lanarkshire population.

The study also showed a lower than expected proportion of threshold ROP. Only three (1.5\%) babies during this 8-year study period showed threshold disease and no babies progressed to stage 4 or 5 ROP. In comparison Fleck et al noted threshold ROP in $14 \%$ (36/258) patients studied between August 1990 and July $1994 .^{6}$ However a number of other studies ${ }^{10,22,24}$ have similarly shown a reduced number of threshold cases including a study from Norway in which no cases from 207 babies with ROP progressed to threshold. ${ }^{9}$ These studies were undertaken on diverse population groups and the varying figures most likely reflect racial and epidemiological differences. Perhaps with advances in modern neonatology we are documenting a decrease in the severity of the condition.

The importance of using both birth weight and gestational age as inclusion criteria for screening of ROP is well recognised..$^{5-13}$ Nodgaard et al has identified gestational age, multiple births, continuous oxygen treatment, and male sex as risk factors for ROP. ${ }^{10}$ Other studies ${ }^{2,4,5}$ have noted a significant association of gestational age and birth weight with retinopathy of prematurity, indicating that the degree of immaturity of the eye is the main predictive factor for the development of ROP. In the present study, severity of ROP appeared to be inversely proportional to birth weight $(P<0.005)$ and gestational age $(P<$ 0.01 ) and none of the other indices were found to have a significant correlation.

In 1995, Fleck et $a l^{6}$ noted that no case of threshold ROP developed in infants of birth weight greater than $1250 \mathrm{~g}$, however they recommended that those $<1250 \mathrm{~g}$ should not be ignored. Goble et $a l^{23}$ questioned the need to screen larger/older neonates. They suggested reducing the upper limits for screening to 1250 grams weight and 29 weeks gestational age at birth, with the possible inclusion of older babies in screening programmes with turbulent clinical course, and if certain sickness criteria such as severe neurological insult, or blood loss are identified. Other authors ${ }^{7,11}$ have suggested lowering the screening criteria even further to less than $1000 \mathrm{~g}$ and 28 weeks.

In the present study a total of 205 babies were screened using the RCO guidelines. ${ }^{12}$ From the results of this study adopting criteria of birth weight $<1251 \mathrm{~g}$ or a gestational age $<30$ weeks would have resulted in the examination of only $150(73 \%)$ babies, 55 less than with the current criteria. Fifty-two babies without ROP, and only two babies with stage 1 and one with stage 2 would not have been screened. All cases with stage 3 ROP (10) and threshold ROP (3) would have been detected. From the statistics in this study the new criteria of $<1250 \mathrm{~g}$ and $<30$ weeks would increase the sensitivity of the screening programme without compromising the specificity.

While it may be acceptable from this study to adopt these criteria, various reports have suggested that threshold ROP can occur in more mature babies. ${ }^{2,20,21,25}$ It must be remembered that the numbers in this Lanarkshire study were relatively small. One of the reasons for the lower amount of stage 3 ROP could be the small sample size and the small number of infants $<1000 \mathrm{~g}$ and $<28$ weeks. The findings may only be characteristic of this particular population grouping, and larger prospective studies within defined regions in the UK would be required to ensure that threshold cases would not remain undetected by lowering the screening criteria.

From this study and other publications there is growing evidence that in order to focus screening on the vision-threatening stages, ophthalmic examination may be safely concentrated in babies with birth weight $<1251 \mathrm{~g}$ and gestational age below 30 weeks. This may provide an effective and efficient means of early diagnosis of treatable ROP.

\section{Conclusion}

In this study population of all stage 3 babies $4.8 \%$ $(10 / 205)$ had a birth weight $<1000 \mathrm{~g}$, gestational age $<28$ weeks. Threshold ROP was noted only in three babies, which shows a lower incidence of severe ROP compared to previous studies. All three babies had a birth weight $<900 \mathrm{~g}$ and gestational age $<26$ weeks. Birth weight $(P<0.005)$ and gestational age $(P<0.01)$ were the only significant risk factors. Our experience suggests further refinement of screening guidelines is needed with a view to design more optimal ROP examination schedules for infants. This would help to ascertain whether birth weight $<1250 \mathrm{~g}$ and gestational age $<30$ weeks could provide a safe and efficient means of detecting treatable ROP. 


\section{References}

1 Schalij-Delfos NE, Zizlmans BL, Wittebol-Post D et al. Screening for retinopathy of prematurity: do former guidelines apply? J Paediatr Ophthalmol Strabismus 1996; 33: $35-38$.

2 Schalij-Delfos NE, Cats BP. Retinopathy of prematurity: the continuing threat to vision in preterm infants. Dutch survey from 1986 to 1994. Acta Ophthalmol Scand 1997; 75: 72-75.

3 Fledelius HC. Retinopathy of prematurity in Frederiksborg County 1988-1990. A prospective investigation, an update. Acta Ophthalmol Suppl 1993; 210: 59-62.

4 Holmstrom G, el Azazi M, Lennerstrand G. A population based, prospective study of the development of ROP in prematurely born children in the Stockholm area of Sweden. Br J Ophthalmol 1993; 77: 417-423.

5 Palmer EA, Flynn JT, Hardy RJ, Phelps DL et al. Incidence and early course of retinopathy of prematurity. The Cryotherapy for Retinopathy of Prematurity Cooperative Group. Ophthalmology 1991; 98: 1628-1640.

6 Fleck BW, Wright E, Dhillon B, Millar GT, Laing IA. An audit of the 1995 Royal College of Ophthalmologists guidelines for screening for retinopathy of prematurity applied retrospectively in one regional neonatal intensive care unit. Eye 1995; 9: 31-35.

7 Fledelius HC. Retinopathy of prematurity in Denmark. Epidemiological considerations and screening limits. Eur J Ophthalmol 1996; 6: 183-186.

8 Gezer A, Sezen F, Serifoglu I, Karacorlu M. Management of retinopathy of prematurity with cryotherapy. Eur J Ophthalmol 1999; 40: 1305-1309.

9 Haugen $\mathrm{OH}$, Markestad T. Incidence of retinopathy of prematurity (ROP) in the Western part of Norway. A population-based retrospective study. Acta Ophthalmol Scand 1997; 75: 305-307.

10 Nodgaard H, Andreasen H, Hansen H, Sorenson HT. Risk factors associated with retinopathy of prematurity (ROP) in northern Jutland, Denmark 1990-1993. Acta Ophthalmol Scand 1996; 74: 306-310.

11 Bianchi PE, Salati R, Guagliano R et al. Review of experience with retinopathy of prematurity from Pavia registry (1990-1993). Eur J Ophthalmol 1996; 6: 187-191.

12 Royal College of Ophthalmologists and British
Association of perinatal medicine. Retinopathy of Prematurity: Guidelines for Screening and Treatment. The report of a joint working party, 1995.

13 An international classification of retinopathy of prematurity. Arch Ophthalmol 1984; 102: 1130-1134.

14 Cryotherapy for cooperative group multicenter trial of cryotherapy for retinopathy of prematurity: one-year outcome, structure and function. Arch Ophthalmol 1990; 108: 1408-1416.

15 Slevin M, Murphy JF, Daly L, O'Keefe M. Retinopathy of prematurity screening, stress related responses, the role of nesting. Br J Ophthalmol 1997; 81: 762-764.

16 Lee SK, Normand C, McMillan D et al. Evidence for changing guidelines for routine screening for retinopathy of prematurity. Arch Pediatr Adolesc Med 2001; 155: 387395.

17 Schalij-Delfos NE, Zijllmans BL, Cats BP. Towards a universal approach for screening of retinopathy of prematurity (ROP). Doc Ophthalmol 1996-97; 92: 137-144.

18 Javitt J, Dei Cas R, Chiang YP. Cost-effectiveness of screening and cryotherapy for threshold retinopathy of prematurity. Pediatrics 1993; 91: 859-866.

$19 \mathrm{Ng}$ YK, Fielder AR, Shaw DE, Levene MI. Epidemiology of retinopathy of prematurity. Lancet 1988; ii: 1235-1238.

20 Bagdoniene R, Surtautiene R. Threshold retinopathy of prematurity in Lithuania. In: Reibaldi A, Di Pietro M, Scuderi A, Malerba E (eds). Progress in Retinopathy of Prematurity. Kugler Publications: Amsterdam/New York, 1997, pp 31-36.

21 Cottrell DG, Inglesby DV, Pollock W. Comments. Eye 1998; 12: 1035.

22 Lim J, Fong DS, Dang Y. Decreased prevalence of retinopathy of prematurity in an inner-city hospital Ophthalmic Surgery and Lasers 1999; 30: 12-16.

23 Goble RR, Jones HS, Fielder AR. Are we screening too many babies for retinopathy of prematurity? Eye 1997; 11: 509-514.

24 Fledelius HC, Dahl H. Retinopathy of prematurity decrease in frequency and severity prevalence trends over 16 years in a Danish county. Acta Ophthalmol Scand 2000; 78: 359-361.

25 Deshpande DA, Chaturvedi M, Gopal L, Ramachandran S, Shanmugasundaram MP. Treatment of threshold retinopathy of prematurity. Ind J Ophthalmol 1998; 46: 1519. 